\title{
Linking Teacher-Student Relationship to Academic Achievement of Senior High School Students
}

\author{
Bismark Mensah $^{1 *}$, Eric Koomson $^{2}$ \\ ${ }^{1}$ Department of Geography Education, University of Education, Winneba, Ghana \\ ${ }^{2}$ Abetifi Presbyterian College of Education, Abetifi Kwahu, Ghana \\ Email: quojoebadu91@gmail.com
}

\begin{abstract}
Students' level of academic engagement and achievement at any level of education is partly knit to the kind of relationships that exist between them and their teachers. The study examined the impact of teacher-student relationship on academic achievement of students in Senior High Schools in Winneba, Ghana. Eighty students were conveniently sampled from two strata whiles data was qualitatively collected using semi-structured interview guide and analyzed thematically. The study uses the four clusters of teacher-student relationship as a framework to discuss the types of relationships that exist in Ghanaian Senior High Schools. The study revealed that connectedness, dependent, peaceful and conflicting teacher-student relationships prevail in Senior High Schools. However, administrative restrictions, and certain attitudes of teachers and students impede the development of effective teacher-student relationship. Whereas positive relationships create environments that augment academic achievement, threatening relationships stifle academic achievement. Teachers should deliberately express concerns both about students' academic and non-academic life, as this makes the latter feel accepted and motivated to improve academic work.
\end{abstract}

Keywords: teacher-student relationship, academic achievement, senior high schools, Winneba, Ghana

\section{Introduction}

Research has indicated that the relationship between teachers and students is an important predictor of academic engagement and achievement. In fact, the most powerful weapon teachers have, when trying to foster a favorable learning climate, is positive relationships with their students. Students who perceive their teachers as more supportive have better achievement outcomes ${ }^{[1-5]}$. Hamre, Pianta, Downer, DeCoster, Mashburn, Jones, Brown, Cappella, Atkins, Rivers, Bracket $\&$ Hamagami ${ }^{[6]}$ assert that teachers ought to be in active engagement in interactions with their students in order for learning to take place .

Among the most influential factors that an individual interacts with, parents and teachers are pivotal and plays significant role in developing the mental picture of self image ${ }^{[7]}$. Based on theories of interpersonal relationships, it is argued that teachers have a fundamental quest for relatedness with the students in their class which can play a significant role in students' self-concept and expectations regarding scholastic achievements and how to make meaningful life after schoo $^{[8]}$. Thus a child's self-esteem is the overall sense of support the child feels from the important people around, particularly their parents and teachers ${ }^{[9]}$. There is a gap between one's ideal self and what he/she perceives to be his or her real self. When the discrepancy is large, the person sees himself as failing to live up to his own goals or values; hence lowering self-esteem which have serious implications on academic performance ${ }^{[9]}$.

Thus, the kinds of relationships teachers establish with their students have a significant toll on their academic achievement ${ }^{[10]}$. The type of relationship between the teacher and the student serves as a connection between the two, providing either a conducive or non-conducive atmosphere for a classroom environment 4 . A study conducted by Marzano ${ }^{[11]}$ revealed that "an effective teacher-student relationship may be the keystone that allows the other aspects to work well" (p. 91). Hence, it is imperative that, greater depth of research about teacher-student relationships and academic performance be made available to guide behaviours within academic environment for optimum instructional outcomes.

In Ghana, educational outcomes are important issues for discussion at the family, school and national levels. Recently, there have been reports on instructors (teachers and lecturers) being fired for establishing negative relationships with

Copyright (C2020 Bismark Mensah, et al.

DOI: https://doi.org/10.37256/ser.122020140

This is an open-access article distributed under a CC BY license

(Creative Commons Attribution 4.0 International License)

https://creativecommons.org/licenses/by/4.0/ 
students, both at the middle and higher levels of education. Although much literature is available on teacher-student relationship and academic performance ${ }^{[7,9-10]}$, have studied the phenomenon in the Ghanaian context especially within the Senior High School context, where students strive for belongingness and recognition. The paper, among exploring the types of teacher-student relationships that exist, examines the extent to which teacher-student relationships affect students' learning at the Senior High School. It goes ahead to ascertain the major challenges to positive teacher-student relationship. The paper also hypothesizes that the more the concern teachers demonstrate towards students' none academic life, the more participatory students become and the better their academic achievement will be.

The paper therefore examines the impact of teacher-student relationship on academic achievement in Senior High Schools in Winneba using the four clusters of teacher-student relationships as identified by Ewnetu and Fisseha ${ }^{[8]}$ as theoretical framework.

\section{Clusters of teacher-student relationship}

Ewnetu and Fisseha ${ }^{[8]}$ and Creasey, Jarvis, and Knapcik ${ }^{[12]}$ classify teacher-student relationship behaviours into four clusters: Connectedness, Anxiety, Independent/Dependent and Peaceful/Conflicting. Connectedness explains the level of closeness between students and teachers. This implies that teachers can establish close relationships with students which may augment student's academic achievement. Anxiety explains that students feel some uneasiness with their teachers. Dependent/Independent relationship is one that shows stronger feeling of either independent or dependent relationship with teachers. With this, students either do or do not think teachers could be depended upon to assist them when they are in a problem as in statements such as "If I were to get into trouble in this class, I do not think this instructor would be very motivated to help me"[13]. Meanwhile, in some cases students may have conflicting relationships with their instructors. Thus, in the case of Peaceful/Conflicting relationship, peacefulness exists in healthy relationships whiles conflict exists in negative relationships ${ }^{[13]}$. Research have indicated that the level of students' academic achievement is a function of the types of teacher-students relationships that exist within the school environment ${ }^{[8,14-16]}$.

\section{Research setting and methods}

There are four Senior High Schools (SHS) in Winneba: Winneba Senior High School, Winneba School of Business, Uncle Rich Senior High School and Zion Girls Senior High School. Among these four, only Winneba Senior High School is public; the other three are privately owned. Whiles public Senior High Schools have permanent teachers, most private Senior High Schools are supported by public school teachers who work on part-time basis. These two categories of teachers will imply different levels of student-teacher relationships. In view of this, the researcher purposively selected Winneba Senior High School whereas a simple random sampling technique was used to select Zion Girls Senior High School from the three private schools. The purposive and simple random sampling techniques ensured that there was the representation of both public and private Senior High School students in the study. The population of students in the selected schools was 2,900. A stratified and quota sampling techniques were used to select eighty (80) students, forty (40) from each school. Whereas the stratified sampling ensured that only form two and three students participated in the study (have established more contact with instructors than SHS One students); the quota sample ensured equal representation of the two schools. The eighty students were finally selected through convenient sampling technique for the purpose of easy accessibility and subsequently interviewed on the types of teacher-students relationships that exist in their schools; challenges to positive teacher-student relationship; and the impact of teacher-student relationship on their academic achievement (see Table 1 for demographic details of participants). A semi-structured interview guide was used for the interview. Responses were qualitatively analyzed using thematic analysis technique. The flexibility and accessibility characteristics of thematic analysis allowed the researcher to systematically identify, organise, and offer insights into patterns of meaning derived from participants' responses ${ }^{[17]}$. The themes were formulated in line with the clusters of teacher-student relationship theory which underpinned the study. The deductive approach to data coding and analysis was used by first generating codes from the responses identifiable with concepts in the clusters of teacher-student relationship theory. The codes were further grouped, reviewed and finally defined for analysis. In the analysis, extracts were drawn from the responses to buttress the defined themes. Participants were made to understand that participating in the study was voluntary and responses given were solely for academic purpose, whiles treating them with high level of confidentiality (no personal identifiers were used on the interview guide). 


\section{Results and discussions}

Contemporary theorists and studies have argued that, real learning is about interaction, growth, and development and not just an isolated student mastery of concepts ${ }^{[14-15]}$. However, whether students' learning would be enhanced or stifled, is a function of how instructors relate with the former ${ }^{[16]}$. This section of the paper therefore discusses the findings of the study with respect to the types of teacher-student relations that exist in Senior High Schools in Winneba, challenges to effective teacher-student relationship and the perceived impact of teacher-student relationships on academic achievement, drawing on the clusters of teacher-student relationships as observed Ewnetu and Fisseha ${ }^{[9]}$ and Creasey et a ${ }^{[12]}$.

\section{Demographic characteristics of participants}

The demographic characteristics of participants which were taken into consideration included sex, age group and level of study. SHS Two and SHS Three as used as categories under the level of study stand for students who are in the second and third years respectively. These data were important to understand the kind of students who were involved in the study. The demographic characteristics of participants are summarised in Table 1.

Table 1. Demographic characteristics of participants

\begin{tabular}{ccc}
\hline Participants' details & Category & Frequency \\
\hline Sex & Male & 48 \\
& Female & 32 \\
Age group & Below 15 years & 10 \\
& 15 -20 years & 67 \\
Level of study & $21-25$ years & 3 \\
& SHS Two & 40 \\
& SHS Three & 40 \\
\hline
\end{tabular}

Source: Fieldwork (2018)

As shown on the table above, out of the 80 participants, 48 were males and 32 were females. This portrays a genderinequality in terms of the representation in the study. However, this does not affect the results of the study since this may have only resulted from the willingness of the students to participate in the study. In Ghana, the average age for entry into Senior High School is 15 years. However, due to some reasons some students may enter Senior High School earlier or later than the average age. From the table above, it could be seen that out of the 80 participants, majority (67) were within the age group of 15-20 years which is the normal range. 10 participants were below 15 years whiles 3 were within the age group of 21-25. 40 each from the two levels participated in the study to ensure equal representation.

\section{Types of teacher student relationships}

The kinds of relationships that exist between instructors and students in Winneba Senior High School and Zion Girls Senior High School are not very different from the ones observed by Ewnetu and Fisseha ${ }^{[9]}$ and Creasey et al ${ }^{[12]}$. Teacherstudent relationships found from the study portrayed connectedness, dependent/Independent, anxiety and peaceful/ conflicting. However, it was found that the peaceful (positive) kind of teacher-student relationship is more dominant in the two schools. This implies that, teachers of the two schools relate very well with the students offering the latter the opportunity to seek for outside-classroom-help on lessons taught. Meanwhile the study further unveiled that, some of the teacher-student relationships were threatening; unhealthy relationships that distorts students' academic work.

In terms of connectedness, it was revealed that, teachers were very close to students. This kind of closeness was revealed to have both negative and positive impact on students' academic achievement. Closeness was revealed to have been established through teachers' recognition and praise of students' effort. Below are what some participants revealed about connectedness in teacher-student relationships:

My teachers relate with me in a good manner. In terms of academic problems they spend a lot of time on me helping me with what I did not understand about what they taught.

To me I will say the way my teachers relate with me is perfect. This is because am able to contact them outside class for explanations on things I did not understand in class.

My teacher is very kind, caring and friendly. She understands me and also she thinks of me. 
Some participants revealed that, they could depend or rely on their teachers for help in times of trouble. In view of this, teachers could offer financial assistance to some needy students whiles providing counseling to students on multifaceted issues. For instance, according to one female participant, a teacher once offered her financial assistance when her money got missing. In her own words,

There was a time my money got lost in school. I went to tell one of my teachers and he helped me out. I was very happy.

Again, the interviews revealed that, some teacher-student relationships are threatening, conflicting. Such relationships are considered to be negative. Relationships described as negative are likely to create unpleasant reactions between the teacher and the student. Some teachers were described to be "cruel". As to what 'cruel' means, whether it implies the usual connotation of the word or not, expresses some kind of unhealthy attitude that instructors express towards the students. At the Senior High School level, some students, particularly the females, appear to be mature and hence some unhealthy relationships may develop between them and teachers. Below are some of the interview responses of some participants:

Some of my teachers relate well but others too are too harsh and I am not happy with that very well. Some teachers tend to favour some students and this is sometimes worrying.

Some teachers appear to show little or no concern about students' welfare. Thus, they often neglect students in some decision process.

Some teachers relate so closely with some students to the extent that, this often results in loss of time on the part of the students to study.

However, some participants indicated that, teachers may adopt threatening relationships as approach to maintaining formal relationships for instructional reasons and also as a tool for calming recalcitrant students. Typically, a participant commented that,

Some students do not want to learn and hence, the teacher has to be "harsh" on them so they will learn hard.

Anxiety was not clearly defined as part of the teacher-student relationships that exist within the study schools. From the analysis, the kinds of teacher-student relationship that pertain in Senior High Schools in Winneba included connectedness, dependent/independent and peaceful/conflicting.

\section{Challenges to positive teacher-student relationship}

Teacher-student relationship has been proven as a vital element in students' academic success. The absence of positive and effective teacher-student relationship is likely to affect students' engagement in the classroom, and consequently, their academic achievement. However, sometimes certain social or physical blocs can hinder effective and positive teacherstudent relationship from prevailing. Such hindrances may originate from teachers, students and administration in the school setting (see Figure1 below). Hindrances originating from teachers and students are both attitudinal causatives, whereas administrative hindrances are a product of reported negative teacher-student relationships. General challenges revealed through the interviews included lack of mutual respect, recalcitrance on the part of some students, development of negative relationships, and administrative restrictions.

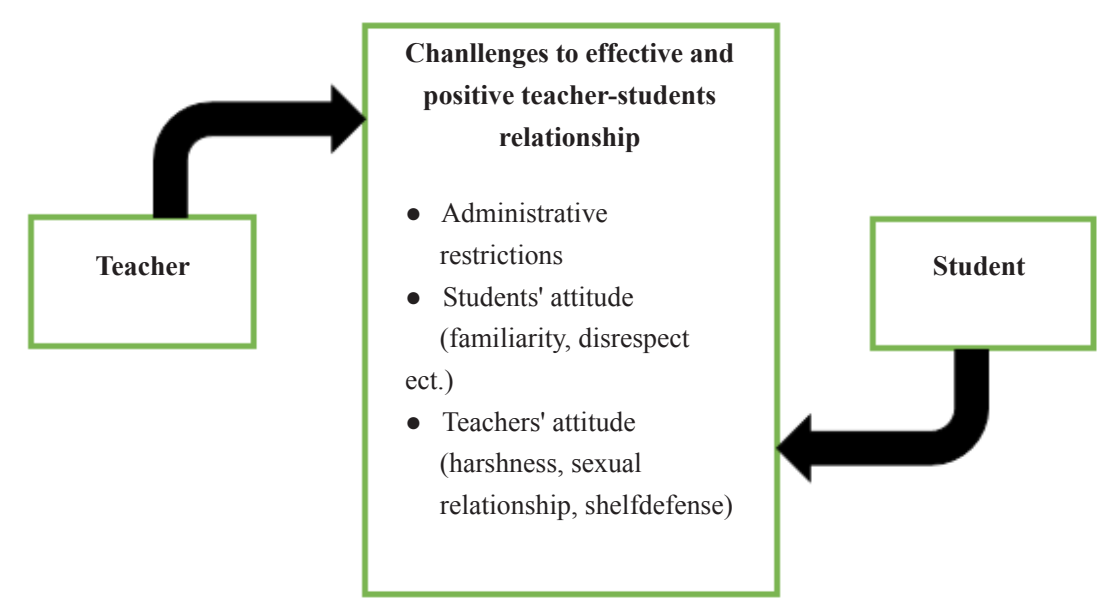

Figure 1. Challenges to effective and positive teacher-student relationship

Soure: fieldwork (2018) 
The interviews showed that one major threat to effective teacher-student relationship in Senior High Schools in Winneba is lack of respect on the part of some students. When students behave untowardly towards teachers, the latter becomes reluctant in establishing expected relationships. Most of the students interviewed reported that, lack of respect on the side of some of their classmates has led to a poor relationship with their teacher. Below are comments from some participants:

Some students sometimes get rude towards teachers when the teacher relate with them; others use that as an opportunity to say anything (example the use of profane words) they like to the teacher.

When teachers relate with some students they take it as an opportunity to disrespect the teacher so it prevents some teachers from relating with students.

Some teachers also refrain from close relationship with female students particularly because of the stigmatization attached to it. A close male teacher-female student relationship may be given negative interpretation, as attested by one participant below.

Also when teachers relate closely to students, some people or students think they are dating, hence, preventing the teacher from relating with students.

The foregoing assertion was given credence by another participant who indicated that, some teachers and students can relate in a way you would not understand whether they are dating or they are a husband and a wife. Thus, the way some teachers relate with students is not good.

Lastly, the interviews showed that, familiarity was another blockage to effective teacher-student relationships. Thus, some students become so familiar with teachers who keep close and informal relationships. Such students tend to offer little attention to the instructions of such teachers (see the next section for details). This when noticed by teachers may cause them to be straightforward with students. This finding is in line with Varga's ${ }^{[13]}$ postulation that a too close relationship with students may yield negative outcomes in the long run. Though this is not always the case, it in no small way accounts for the reason some teachers do not build the connectedness type of relationship with students.

\section{Impact of teacher-student relationship on academic achievement}

The level of academic engagement of student is proven to be a function of teacher-student relationship which may be intentionally or unintentionally established ${ }^{[15-16]}$. In this study academic achievement was not quantified. However, responses generated through the detailed interviews proved that indeed there is a relationship between students' academic engagement and achievement, and their relationship with teachers. Obviously, the interviews revealed that whereas positive teacher-student relationship (Peaceful, Connectedness, Dependent) creates an environment that augments academic engagement and achievement, negative teacher-student relationship (Independent, Conflicting, Anxiety) creates an environment that stifles academic engagement and achievement of students.

With the positive impact, participants indicated that a good teacher-student relationship, one that ensures that students' concerns-both academic and non-academic-are of priority, lead to increased students' academic engagement and achievement. Below are some of the responses participants gave regarding the perceived positive impact of a positive teacher-student relationship:

In some situations, a good teacher-student relationship may grant the student the opportunity to seek help in some subject areas the student is experiencing difficulties. This can help the student to improve.

Some students have issues from their homes which they need to share with someone. Thus, by relating with a teacher, he or she can share that worry and seek counseling. This gives them sound mind for learning. And also, some have problems in some subjects, through that they may be assisted by the teacher in order to improve.

Some teachers relate with some students in a good manner that helps the student to learn hard. This is because they know that if they don't learn, the teacher will not relate with them again.

From the above responses, it is clear that students need teachers to share issues with, which may not necessarily be academics. It is believed that, when they had shared these issues with their teachers, they got sound mind to focus on their studies, thereby, augmenting their academic achievement. A positive teacher-student relationship is an extrinsic motivation to students whiles creating the opportunity for students to easily approach their teachers for clarifications on instructional problems.

Meanwhile, some of the students interviewed indicated that sometimes the kind of relationship teachers build with students are potentially disincentive to learning. Too close relationship with students may cause reduced attention to studies on the part of the students. For instance, some participants indicated that,

Some teachers relate with some students to a point that, they award marks to such students even when they do not 
perform class exercises or even write examination. This makes the student feel lazy to learn.

Some teachers develop unhealthy relationships with students which affect their academic performance. This is because, anytime the teacher stands in front of the class, the student may say "oh after all, he will gift me marks and so why should I pay attention to him".

When teachers condemn students, the students feel unwanted or useless and therefore do not put much effort in their academic work anymore. When a teacher keeps condemning a student, it affects his or her academic performance negatively. Also, when teachers become too strict on students, it may affect their academic performance.

From the above responses, it is glaringly clear that when teacher-student relationships become distorted, the resultant effect on students' academic engagement and achievement is undesirable.

\section{Conclusion}

Teacher-student relationship is an integral part of the total educational process which has a toll on the level of students' academic engagement and achievement. The paper basically examined the impact of teacher-student relationship on academic achievement. It particularly explored the types of teacher-student relationships and the challenges to effective teacher-student relationship.

The types of teacher-student relationships that exist in Senior High Schools in Winneba included connectedness, dependent, peaceful and conflicting. Students were so connected to their teachers that, approaching them for further discussions was not difficult. Students could depend on their teachers for help in times of trouble. However, some teacherstudent relationships were threatening as far as students' academic achievement is concerned.

There are a couple of challenges to effective teacher-student relationship: administrative restrictions, and teachers' attitude and students' behaviours which are assumed to be threatening.

Whereas a positive teacher-student relationship creates an enabling environment for academic engagement and achievement, the lack of it stifles the level of academic engagement and achievement to some extent. Students require some sense of belonging to enhance their academic work

Based on the outcome of this study, it is important that, as part of their efforts in improving students' academic work, teachers should endeavor to deliberately establish good relationships with students. This could be done by expressing concerns not only about students' academic work but also about other issues that confront them from the home. This would make students feel accepted and become motivated to cooperate and improve their academic work.

\section{Acknowledgement}

This paper is part of the assessment requirements for Educational Leadership and Policy course under the MPhil Geography Education programme at the University of Education, Winneba funded by the researcher and supervised by Dr. Dandy Dampson.

\section{References}

[1] Boynton, M., Boynton, C. Developing positive teacher-student relationships. In Educator's Guide to Preventing and Solving Discipline Problems. 2005. Available from: http://www.ascd.org/publications/books/105124/chapters/ Developing_Positive_Teacher-Student_Relations.aspx.

[2] Spilt, J. L., Koomen, H. M., Y., Thijs, J. T. Teacher well-being: The importance of teacher-student relationships. Educational Psychology Review. 2011; 23(4): 457-477.

[3] Skinner, E., Greene, T. Perceived control, coping, and engagement. In: T. L. (eds.) Good 21st Century Education: A Reference Handbook. Thousand Oaks, CA: SAGE Publications Ltd; 2008; 2: I-121-I-130.

[4] Rimm-Kaufman, S., Sandilos, L. Improving students' relationships with teachers to provide essential supports for learning. 2012. Available from: http://www.apa.org/education/k12/relationships.aspx?item=1.

[5] Gehlbach, H., Brinkworth, M., Harris, A. Changes in teacher-student relationships. British Journal Of Educational Psychology. 2012; 82(1): 690-704.

[6] Hamre, B., Pianta, R., Downer, J., DeCoster, J., Mashburn, A., Jones, S., Brown, J., Cappella, E., Atkins, M., Rivers, S., Bracket, M., Hamagami, A. Teaching through interactions: Testing a Developmental Framework of Teacher Effectiveness in over 4,000 Classrooms. The Elementary School Journal. 2013; 113: 461-487.

[7] Pianta, R. C., Hamre, B., Stuhlman, M. Relationships between teachers andchildren. In: W. Reynolds, G. Miller. (eds.) Comprehensive handbook of psychology: Educational psychology. Hoboken, NJ: Wiley \& Sons, Inc; 2003. p.199-234. 
[8] Ewnetu, S., Fisseha, M. The Teacher Relationship Behaviour and Parenting Style Correlates of Students' Scholastic Achievement at Grade Seven English. Ethiop. J. Education. \& Science. 2008; 4(1).

[9] Tam, C. L., Fatimah, Y. The Effects of Family Functioning on Self-Esteem of Children. European Journal of Social Sciences. 2009; 9(4): 1-10.

[10] Hughes, J., Kwok, O. Influence of student-teacher and parent-teacher relationships on lower achieving readers' engagement and achievement in the primary grades. Journal of Educational Psychology. 2007; 99: 39-51.

[11] Marzano, R. J. What works in schools. Alexandria, VA: Association for Supervision and Curriculum Development; 2003.

[12] Creasey, G., Jarvis, P., Knapcik, E. A measure to assess student-instructor relationships. International Journal for the Scholarship of Teaching and Learning. Contructivism: theory, perspectives and practice. New York: Teachers College Publishing; 2009; 3(2).

[13] Varga, M. Effects of Teacher-Student Relationships on the academic engagement of students. A thesis submitted to Goucher College. 2017.

[14] Willingham, W. W., Pollack, J. M., Lewis, C. Grades and test scores: accounting for observed differences. Journal of Educational Measurement. 2002; 39(1): 1-37.

[15] Grobe, C., Bishop, G. School Attributes and Student Achievement. New Brunswick: Department of Education; 2001.

[16] Haycock, K. Good Teaching Matters A Lot. Santa Cruz: The Center for the Future of Teaching \& Learning; 1998.

[17] Braun, V., Clarke, V. Thematic analysis. In: H. Cooper, P. M. Camic, D. L. Long, A. T. Panter, D. Rindskopt, K. J. Sher. (eds.) APA handbook of research methods in psychology, Vol. 2. Research designs: Quantitative, qualitative, neuropsychological, and biological. 2012. p. 57-71. American Psychological Association. https://doi. org/10.1037/13620-004. 